Original Article

\title{
SYNTHESIS, CHARACTERIZATION AND ANTIOXIDANT ACTIVITY OF POTASSIUM CIS- DIAQUA-BIS (OXALATO) CHROMATE (III) WITH LEVODOPA AND CARBIDOPA
}

\author{
SUDHANSHU SEKHAR ROUT ${ }^{*}$, SOVAN PATTANAIK ${ }^{\mathrm{a}}$, SUDAM CHANDRA SI ${ }^{\mathrm{a}}$, PRAKASH MOHANTY ${ }^{\mathrm{b}}$
}

aSchool of Pharmaceutical Sciences, Siksha 'O' Anusandhan deemed to be University, Bhubaneswar, India, 'Department of Chemistry,

Ravenshaw University, Cuttack, India

Email: sudhanshurout@soauniversity.ac.in

Received: 08 Sep 2017 Revised and Accepted: 22 Nov 2017

\section{ABSTRACT}

Objective: These studies focus on the interaction between two clinically active antiparkinsonian drugs L-dopa (L) and carbidopa (C) with the cis$\left[\mathrm{Cr}\left(\mathrm{C}_{2} \mathrm{O}_{4}\right)_{2}\left(\mathrm{H}_{2} \mathrm{O}\right)_{2}\right]$ and evaluation of the synthesized product from a coordination chemistry aspect with respect to the possibility of its antioxidant activity and its therapeutic application in the treatment of Parkinson disease.

Methods: The resulting synthesized complexes were characterized by UV-VIS and FTIR spectroscopy. Evaluation of antioxidant activities of this cis$\left[\mathrm{Cr}\left(\mathrm{C}_{2} \mathrm{O}_{4}\right)_{2}\left(\mathrm{H}_{2} \mathrm{O}\right)_{2}\right]^{-}$-L-dopa(ML), cis- $\left[\mathrm{Cr}\left(\mathrm{C}_{2} \mathrm{O}_{4}\right)_{2}\left(\mathrm{H}_{2} \mathrm{O}\right)_{2}\right]^{-}$-carbidopa(MC) and standard butylated hydroxytoluene (BHT) were carried out by using 1,1-diphenyl-1-picrylhydrazyl free radical (DPPH), 2,2-azinobis (3-ethylbenzothiazoline-6-sulfonic acid) (ABTS) radical cations and hydrogen peroxide method.

Results: The results of spectral analysis of the synthesized products indicate that complexes have a $\operatorname{Cr}(\mathrm{III})$ ion coordinated via the carboxylic and amino group. In the reduction of radical DPPH and the formation of radical monocation ABTS ${ }^{+}$the ability to scavenge radical was measured in these experiments by the discoloration of the solution. However, in hydrogen peroxide method, the increased in absorbance showing its scavenging potential. The scavenging capacity of the test compounds and standard on the DPPH, ABTS ${ }^{+}, \mathrm{H}_{2} \mathrm{O}_{2}$ decreased in the order BHT $>\mathrm{ML}>\mathrm{MC}>\mathrm{C}>\mathrm{L}$ which were 98.4, 96.4, 86.4, 68.3, 49.7\% for DPPH, BHT $>$ ML $>$ L $>$ MC $>$ C which were 99.3, 96.9, 96.3,66.6, 53.4\% for ABTS + , BHT $>$ ML $>$ MC $>$ L $>C$ which were $68.8 \%, 52.4 \%, 49.6 \%, 43.1 \%$ and $37.7 \%$ for $\mathrm{H}_{2} \mathrm{O}_{2}$ at the concentration of $50 \mu \mathrm{g} / \mathrm{ml}$, respectively.

Conclusion: The experimental findings showed that cis-[Cr( $\left.\left(\mathrm{C}_{2} \mathrm{O}_{4}\right)_{2}\left(\mathrm{H}_{2} \mathrm{O}\right)_{2}\right]^{-}$-levodopa and cis-[ $\left[\mathrm{Cr}\left(\mathrm{C}_{2} \mathrm{O}_{4}\right)_{2}\left(\mathrm{H}_{2} \mathrm{O}\right)_{2}\right]^{-}$-carbidopa are having higher antioxidant potential than Levodopa and carbidopa although not superior to that of standard compound.

Keywords: Levodopa, Carbidopa, Cis-diaqua-bis(oxalato)chromate(III), DPPH, ABTS

(C) 2018 The Authors. Published by Innovare Academic Sciences Pvt Ltd. This is an open access article under the CC BY license (http://creativecommons.org/licenses/by/4.0/) DOI: http://dx.doi.org/10.22159/ijpps.2018v10i1.22464

\section{INTRODUCTION}

Parkinson disease (PD), which is considered to be the most common neurodegenerative movement disorder, causes selective degeneration of nigrostriatal dopamine neurons. PD is characterized by the decrease level of dopamine (DA) and hence L-dopa (L) is administered as a supplementation of DA since last $50 \mathrm{y}$. But L-dopa is decarboxylated in the peripheral regions, so to avoid this decarboxylation L-dopa is generally administered in combination with peripheral dopa decarboxylase inhibitors like carbidopa (C) [1]. Several factors affecting the mechanism of neurodegeneration in PD which includes mitochondrial impairment and oxidative stress [2]. In the state of oxidative stress, resulting generation of the reactive oxygen species (ROS) surpasses the capacity of the endogenous antioxidant system. ROS are chemically reactive molecules that are derived from oxygen, including free radicals, such as $\mathrm{O}_{2}$, hydroxyl radicals $(\mathrm{OH} \cdot)$ and non-free-radical species, such as $\mathrm{H}_{2} \mathrm{O}_{2}$. Singlet oxygen $\left(\mathrm{1}^{2}\right)$ species are also forms of activated oxygen. These molecules are behave as deleterious factors inducing cellular injury and ageing [3]. According to some recent evidence, oxidative stress is one of the major reasons for oxidative damage to proteins, lipids, and nucleic acids in both the brain and the peripheral tissues in PD. With age, the accumulation of these biomolecules occurs and that becomes a significant risk factor for this disease. In accordance with the role of reactive oxygen species in the progression of PD, the antioxidants can potentially serve as a disease treatment [4].

Antioxidants are having a key role in the prevention of human diseases and may function as scavengers of free radicals. These are capable even in small quantities, to prevent or reduce the oxidative destruction of biologically important compounds such as lipids, proteins, and nucleic acids [5]. Therefore, the importance of the search for antioxidants has greatly increased in the recent years. Transition metal complexes contain oxo and aza groups are showing some characteristic chemical properties and biological activities such as being models for metalloproteins and oxygen carrier systems [6]. Some recent studies reveal that metal complexes can be used as antioxidants as they could restore the redox balance in the damaged cells and organs by scavenging of excess ROS [7]. There is continuous research has been carried out in the fundamental chemistry of chromium compounds. Chromium has its insulinenhancing activity when present in biological systems; has generated a considerable amount of interest in its research [8].

In the present study, an attempt has been made to evaluate the antioxidant activity of the $\operatorname{Cr}(\mathrm{III})$ complexes of L-Dopa (ML) and carbidopa (MC) and compared with standard compounds like BHT. The antioxidant activities of the metal complexes along with the standard compounds were evaluated in a series of in vitro tests: DPPH free radical scavenging activity, ABTS ${ }^{+}$radical scavenging activity and $\mathrm{H}_{2} \mathrm{O}_{2}$ scavenging activity. We have made the detailed studies of the complex forming properties of L-dopa with $\mathrm{Cr}$ (III) and subsequently, the bonding conditions relating to the complexes formed and stability of the complex was also reported [9].

\section{MATERIALS AND METHODS}

\section{Chemicals and physical measurements}

(S)-2-amino-3-(3,4-dihydroxyphenyl) propanoic acid (L-Dopa) and (2S)-3-(3,4-dihydroxyphenyl)-2-hydrazino-2-methylpropanoic acid (carbidopa) was obtained from Dr Reddy's Lab, Hyderabad, India. The metal salt $\mathrm{Cr}\left(\mathrm{NO}_{3}\right)_{3} 6 \mathrm{H}_{2} \mathrm{O}$, potassium dichromate $\left(\mathrm{K}_{2} \mathrm{Cr}_{2} \mathrm{O}_{7}\right.$ ), oxalic acid, ethanol, potassium persulfate $\left(\mathrm{K}_{2} \mathrm{~S}_{2} \mathrm{O}_{8}\right), 2,2$ '-azino-bis(3-ethylbenzothiazoline-6-sulfonic acid) (ABTS), the stable free radical 1,1-diphenyl-2- 
picrylhydrazyl (DPPH) were purchased from Merck. All other solvents and buffer constituents were of highest available purity and they were used without further purification. UV-Vis spectra were recorded by JASGO-V 630 Spectrophotometer in the range $800-200 \mathrm{~nm}$. FTIR spectra were recorded in JASGO FT/IR-4100 spectrophotometer in the range $4000-400 \mathrm{~cm}^{-1}$. pH of the solutions was the measurement by using SYSTRONICS digital $\mathrm{pH}$ meter 335 equipped with a combination of glass $\mathrm{Ag} / \mathrm{AgCl} / \mathrm{Cl}-\left(3 \mathrm{~mol} \mathrm{dm}^{-3} \mathrm{NaCl}\right)$ electrode. It was calibrated with standard buffers of pH 4.0, 7.0 and 9.0 (Merck).

\section{Synthesis of $\mathrm{K}\left[\mathrm{Cr}\left(\mathrm{C}_{2} \mathrm{O}_{4}\right)_{2}\left(\mathrm{H}_{2} \mathrm{O}\right)_{2}\right]_{3} \mathrm{H}_{2} \mathrm{O}$}

$\mathrm{K}\left[\mathrm{Cr}\left(\mathrm{C}_{2} \mathrm{O}_{4}\right)_{2}\left(\mathrm{H}_{2} \mathrm{O}\right)_{2}\right] 3 \mathrm{H}_{2} \mathrm{O}$ was prepared as per the reported method [10]. Potassium dichromate $(2 \mathrm{~g})$ and oxalic acid dehydrate $(6 \mathrm{~g})$ were mixed and placed in an evaporating disc which has already contained 5-6 drops of water. It was covered with a watch glass and placed on a hot plate. After a few seconds, a vigorous exothermic reaction occurred and the reaction mixture became a dark viscous liquid. When the reaction was completed ethanol $(15 \mathrm{ml})$ was added and stirred. As the product remained partly as oil another $10 \mathrm{ml}$ of ethanol was added after removal of the supernatant alcohol. Then the product was filtered, washed with ethanol and dried in a vacuum desiccator. The product appears almost black in diffuse daylight and deep green in the artificial light.

\section{Synthesis of L-dopa and carbidopa bonded $\operatorname{Cr}(\mathrm{III})$ complex}

The synthesized products of levodopa and carbidopa complex with $\mathrm{Cr}(\mathrm{III})$ was obtained as per the reported method [11]. The prepared Potassium cis-[ $\left.\mathrm{Cr}\left(\mathrm{C}_{2} \mathrm{O}_{4}\right)_{2}\left(\mathrm{OH}_{2}\right)_{2}\right]$-complex $(0.01 \mathrm{~mol})$ was mixed with $(0.05 \mathrm{~mol}) \mathrm{L}$-dopa and carbidopa separately in a small volume of water. $\mathrm{pH}$ of the solutions was maintained at 5.0 and the solution was heated in a thermostat at $50^{\circ} \mathrm{C}$ for $5 \mathrm{~h}$. Then the solutions were kept in a desiccator for slow evaporation of solvent and crystals were formed after few days. The crystals were washed several times with ethanol, dry ether and dried.

\section{1,1-diphenyl-2-picrylhydrazyl (DPPH) free radical scavenging activity}

For the evaluation of antioxidant activity, the method of Blois [12] which is previously described by Gülçin [13] was used with slight modification. $0.1 \mathrm{mmol}$ solution of $\mathrm{DPPH}$ in ethanol was prepared and an aliquot of $1 \mathrm{ml}$ of this solution was added to $3 \mathrm{ml}$ solutions of $\mathrm{Cr}$ (III) complex of L-Dopa and carbidopa in water at different concentrations $(10-50 \mu \mathrm{g} / \mathrm{ml})$. The solutions were incubated in dark for $30 \mathrm{~min}$ and then the absorbance was measured at $517 \mathrm{~nm}$ against blank samples lacking scavengers.

The capability to scavenge the DPPH was calculated using the following equation:

\section{DPPH'scavenging effect $(\%)=\left(1-A_{s} / A_{c}\right) \times 100$}

Where $A_{c}$ is the absorbance at $517 \mathrm{~nm}$ of the reaction (containing all the reagents except the test compound) and $\mathrm{A}_{\mathrm{s}}$ is the absorbance at $517 \mathrm{~nm}$ containing the test compound i. e. Cr(III) complex of L-Dopa and carbidopa.

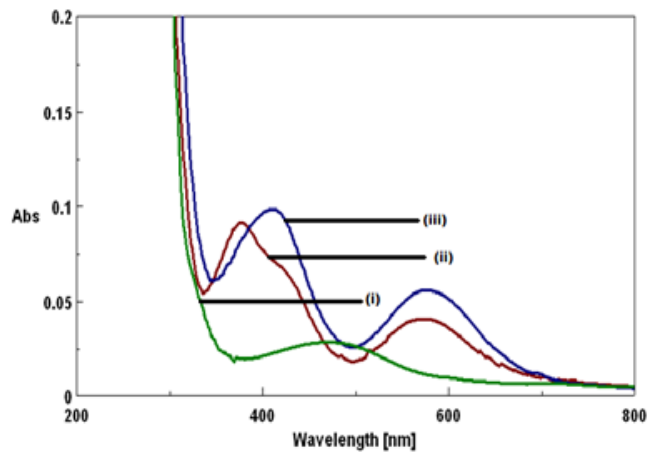

a

\section{ABTS radical cation decolorization assay}

The ABTS+scavenging activity was determined by spectrophotometric analysis according to the method of Re and co-workers [14]. $2 \mathrm{mmol}$ ABTS in $\mathrm{H}_{2} \mathrm{O}$ was reacted with $2.45 \mathrm{mmol}$ potassium persulfate $\left(\mathrm{K}_{2} \mathrm{~S}_{2} \mathrm{O}_{8}\right)$, and the mixture was allowed to stand in the dark at room temperature for $6 \mathrm{~h}$ before use. Before usage, the $\mathrm{ABTS}^{++}$solution was diluted in phosphate buffer $(\mathrm{pH} 7.4)$ to give an absorbance of $0.700 \pm 0.025$ at $734 \mathrm{~nm}$. Then $1 \mathrm{ml}$ of ABTS ${ }^{+}$solution has added to $3 \mathrm{ml}$ solution of $\mathrm{Cr}(\mathrm{III})$ complexes of L-Dopa and carbidopa in ethanol at different concentrations $(10-50 \mu \mathrm{g} / \mathrm{ml})$. After $30 \mathrm{~min}$ of mixing the absorbance was recorded at $734 \mathrm{~nm}$ calculated for each concentration relative to a blank absorbance (ethanol). The scavenging capability of the ABTS ${ }^{+}$radical was calculated using the following equation:

$$
\text { ABTS+scavenging effect }(\%)=\left(1-A_{s} / A_{c}\right) \times 100
$$

Where $A_{c}$ is the absorbance of a control lacking the scavenger and $A_{s}$ is the absorbance of the remaining ABTS ${ }^{+}$in the presence of scavengers [15].

\section{Hydrogen peroxide scavenging activity}

The $\mathrm{H}_{2} \mathrm{O}_{2}$ scavenging ability of the $\mathrm{Cr}(\mathrm{III})$ complexes of L-Dopa and carbidopa was determined according to the method of Ruch et al. [16]. A $40 \mathrm{mmol} \mathrm{H}_{2} \mathrm{O}_{2}$ solution was prepared in a buffer solution having $\mathrm{pH}$ 7.4. $\mathrm{Cr}(\mathrm{III})$ complex of L-Dopa and carbidopa at different concentrations $(10-50 \mu \mathrm{g} / \mathrm{ml})$ in $3.4 \mathrm{ml}$ phosphate buffer was added to $0.6 \mathrm{ml}$ of $\mathrm{H}_{2} \mathrm{O}_{2}$ solution $(40 \mathrm{mmol})$ and the absorbance of the mixture solutions was recorded at $230 \mathrm{~nm}$. A blank solution is prepared by taking sodium buffer solution but without $\mathrm{H}_{2} \mathrm{O}_{2}$.

The percentage scavenging activity of $\mathrm{H}_{2} \mathrm{O}_{2}$ by the $\mathrm{Cr}$ (III)-ligand complexes and standard ligand compounds was calculated using the following equation:

$$
\mathrm{H}_{2} \mathrm{O}_{2} \text { scavenging effect }(\%)=\left(1-\mathrm{A}_{\mathrm{s}} / \mathrm{A}_{\mathrm{c}}\right) \times 100
$$

Where $A_{c}$ is the absorbance of the control and $A_{s}$ is the absorbance of the metal complexes.

\section{RESULTS AND DISCUSSION}

\section{Characterization of the $\mathbf{C r}(\mathrm{III})$-complexes}

The presence of metal ions in the complexes accelerates the activity and efficacy of organic therapeutic agents [17]. The therapeutic potential of metal complexes depends on the ligand as well as nature of metal ions [18]. Some literature revealed that different ligands and different complexes synthesized from same ligands with different metal ions possess different biological properties [17, 19-21]. Upon testing metal complexes as antioxidants the test results show that they could effectively facilitate the scavenging of excess ROS. Therefore, it is strongly required to design novel metal complexes as potential therapeutic candidates for prevention of oxidative stress [7]. The absorption spectra of ML and MC indicated the formation of new complexes, which showed the shifting of $\lambda_{\max }$ from 472 to $413 \mathrm{~nm}$ (blue shift) (fig. 1a) and from 378 to $413 \mathrm{~nm}$ (redshift) (fig. 1b) respectively.

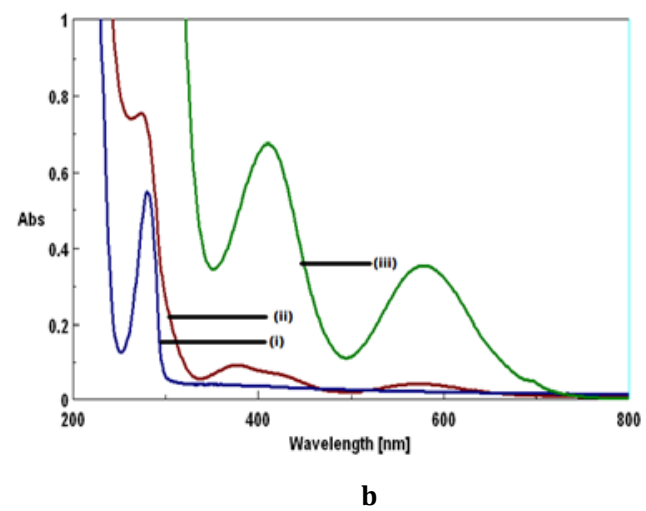

Fig. 1a: An overlay scanning plot: (i) L-dopa (ii) $\mathrm{Cr}$ (III) complex with L-dopa (ML) (iii) $\mathrm{K}\left[\mathrm{Cr}\left(\mathrm{C}_{2} \mathrm{O}_{4}\right)_{2}\left(\mathrm{H}_{2} \mathrm{O}\right)_{2}\right]_{3} \mathrm{H}_{2} \mathrm{O}$ and 1b (i)Carbidopa (ii) $\mathrm{K}\left[\mathrm{Cr}\left(\mathrm{C}_{2} \mathrm{O}_{4}\right)_{2}\left(\mathrm{H}_{2} \mathrm{O}\right)_{2}\right]_{3} \mathrm{H}_{2} \mathrm{O}$ (iii) $\mathrm{Cr}(\mathrm{III})$ complex with carbidopa(MC) 
The FTIR spectra of the products retained most of the peaks of LDopa and carbidopa. However, in ML the carboxylate $v_{(\mathrm{C}=0)}$ for the product complex is observed at $1541 \mathrm{~cm}^{-1}$ a $29 \mathrm{~cm}^{-1}$ downshift compared to the free L-Dopa. A $142 \mathrm{~cm}^{-1}$ downshift to $3232 \mathrm{~cm}^{-1}$ for $v_{(\mathrm{N}-\mathrm{H})}$ is consistent with bonding through the $\mathrm{N}$ atom. Similarly, in MC the peak observed at $1683 \mathrm{~cm}^{-1}$ which shifted from $1633 \mathrm{~cm}^{-1}$ compared to the free carbidopa which indicates the coordination of carboxylate group of carbidopa with $\operatorname{Cr}(\mathrm{III})$ and a $89 \mathrm{~cm}^{-1}$ downshift to $3446 \mathrm{~cm}^{-1}$ shows the bonding of the $\mathrm{Cr}(\mathrm{III})$ through the $\mathrm{N}$ atom. The tentative structure of the L-dopa bonded chromium (III) and carbidopa bonded $\mathrm{Cr}$ (III) complexes are shown in fig. $2 \mathrm{a}$ and $2 \mathrm{~b}$.<smiles>CCCOC1(OC(=O)C(=O)O)NC(Cc2ccc(O)c(O)c2)C(=O)O1</smiles>

a<smiles>COc1ccc(CC2(C)NNC3(OC(=O)C(=O)O3)OC(=O)C2=O)cc1O</smiles>

b

Fig. 2a and 2b: tentative structure of $\mathrm{Cr}$ (III) complex with L-dopa (ML), $\mathrm{Cr}$ (III) complex with carbidopa (MC)

\section{DPPH radical scavenging assay}

For the evaluation of the ability of antioxidants to scavenge free radicals, $\mathrm{DPPH}^{-}$radical scavenging assay is commonly employed [22]. Radical scavenging activity of the synthesized $\mathrm{Cr}$ (III) complexes of L-Dopa and carbidopa was determined by 1,1-diphenyl-2-picrylhydrazil (DPPH) and compared to that of standard compound. The $\mathrm{DPPH}^{\cdot}$ radical absorbs at $517 \mathrm{~nm}$ but when it reduced by an antioxidant(HA) or a radical species(RA') its absorption decreases, as a result, stable DPPH forms yellow colored diphenyl-picrylhydrazine [23].

$$
\begin{aligned}
& \mathrm{DPPH}+\mathrm{AH} \longrightarrow \mathrm{DPPH}-\mathrm{H}+\mathrm{A}^{*} \cdot \ldots . . . .(1) \\
& \mathrm{DPPH}^{+}+\mathrm{R}^{\cdot} \longrightarrow \text { DPPH-R................(2) }
\end{aligned}
$$

Upon transfer of a hydrogen atom or an electron to the odd electron in DPPH; the absorbance at $517 \mathrm{~nm}$ decreases proportionally as the non-radical forms of DPPH increases [24].

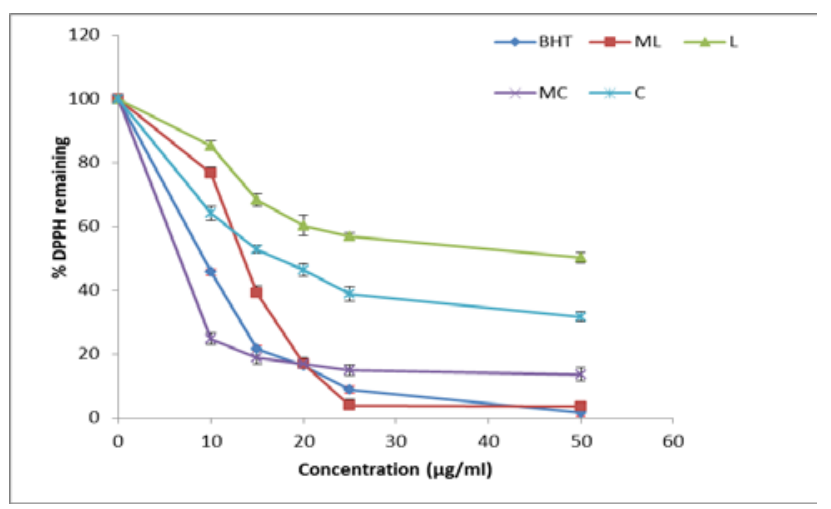

Fig. 3: Free radical scavenging activity of L-dopa (L), carbidopa (C), Cr(III) complex with L-dopa (ML), Cr(III) complex with carbidopa (MC) and BHT(butylated hydroxytolune) on DPPH radicals, results are mean \pm standard deviation of three parallel measurements and data are evaluated by using one-way analysis of variance (ANOVA)

As seen in fig. 3 the test compounds effectively scavenge DPPH radicals in a concentration-dependent manner $(10-50 \mu \mathrm{g} / \mathrm{ml})$. There is a significant decrease $(\mathrm{p}<0.01)$ in the concentration of DPPH radical due to scavenging activity of L-dopa, carbidopa with their $\mathrm{Cr}$ (III) complexes and standard compound. The scavenging capacity of the test compounds and standard on the DPPH radical decreased in the order $\mathrm{BHT}>\mathrm{ML}>\mathrm{MC}>\mathrm{C}>\mathrm{L}$ which were 98.4, 96.4, 86.4, 68.3, $49.7 \%$ at the concentration of $50 \mu \mathrm{g} / \mathrm{ml}$, respectively.

\section{ABTS radical scavenging assay}

ABTS forms a relatively stable free radical, which decolorizes in its non-radical form. The basis of this spectroscopic assay is the generation of ABTS radical cation [25-27].
Initially, ABTS radical cation (ABTS-+) is generated from its stable form, prior to reaction with standard antioxidants and presumed test compounds.

Generation of blue/green $\mathrm{ABTS}^{+}$chromophore involves the reaction between ABTS and potassium persulphate and the following equations represent the reaction as

$$
\begin{aligned}
& \mathrm{S}_{2} \mathrm{O}_{8}{ }^{2+}+\mathrm{ABTS} \longrightarrow \mathrm{SO}_{4}{ }^{2+}+\mathrm{SO}_{4}{ }^{--}+\mathrm{ABTS}^{++} \ldots \\
& \mathrm{SO}_{4}{ }^{-+}+\mathrm{ABTS} \longrightarrow \mathrm{SO}_{4}{ }^{2+}+2 \mathrm{ABTS}^{++} \ldots \ldots \ldots
\end{aligned}
$$

The overall reaction represented by

$$
\mathrm{S}_{2} \mathrm{O}_{8}{ }^{2+}+2 \mathrm{ABTS} \longrightarrow 2 \mathrm{SO}_{4}{ }^{2+}+2 \mathrm{ABTS}^{+}
$$


Here, to a preformed ABTS radical solution, an antioxidant is added and the remaining $\mathrm{ABTS}^{++}$is quantified spectrophotometrically at $734 \mathrm{~nm}$ after a fixed period of time [28].

All the test compounds exhibited effective radical scavenging activity. Fig. 4 illustrates that the test compounds effectively scavenge ABTS ${ }^{+}$radicals in a concentration-dependent manner (10-
$50 \mu \mathrm{g} / \mathrm{ml}$ ). There is a significant decrease in the concentration of $\mathrm{ABTS}^{+}$due to the scavenging activity of L-dopa, carbidopa, with their $\mathrm{Cr}(\mathrm{III})$ complexes and standard compound. In addition to this the scavenging capacity of the test compounds and standard on the $\mathrm{ABTS}^{+}+$decreased in the order $\mathrm{BHT}>\mathrm{ML}>\mathrm{L}>\mathrm{MC}>\mathrm{C}$ which were 99.3 $96.9,96.3,66.6,53.4 \%$ at the concentration of $50 \mu \mathrm{g} / \mathrm{ml}$ respectively.

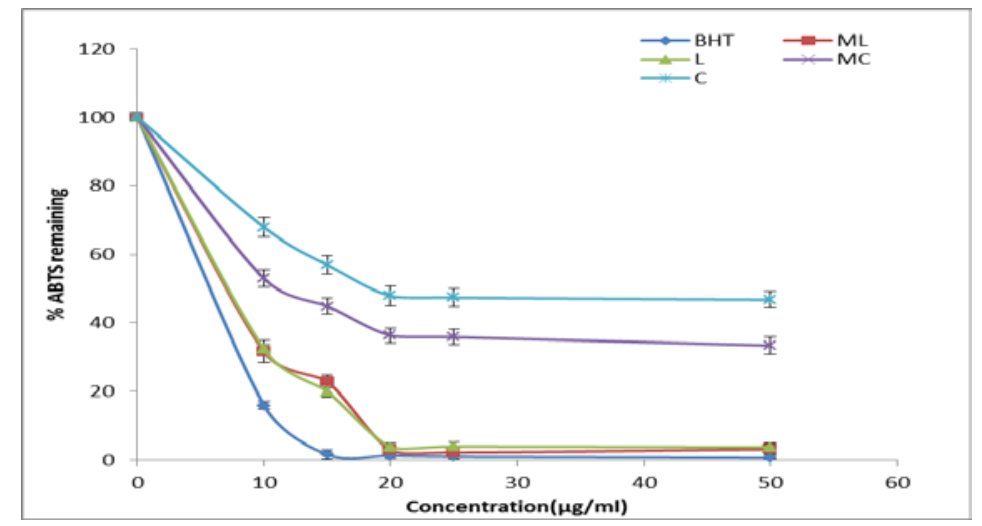

Fig. 4: Scavenging effect of L-dopa(L),carbidopa(C), Cr(III) complex with L-dopa(ML), Cr(III) complex with carbidopa(MC) and BHT(butylated hydroxytolune) on the stable $\mathrm{ABTS}^{+}$. Results are mean \pm standard deviation of three parallel measuremets and data are evaluated by using one-way analysis of variance(ANOVA)

\section{Hydrogen peroxide scavenging activity}

Although hydrogen peroxide is not very reactive oxygen species but due to its high penetrability of the cell membrane, generates hydroxyl radicals upon reaction with ferrous ion or superoxide anion radical in the cell [29]. Many oxidizing enzymes like superoxide dismutase can generate hydrogen peroxide in vivo which can cross membranes and may slowly oxidize a number of molecules. According to some recent evidence $\mathrm{H}_{2} \mathrm{O}_{2}$ is toxic, it can attack many cellular energy producing systems and it also induces cell death in vitro [30]. According to this method upon oxidation of $\mathrm{H}_{2} \mathrm{O}_{2}$ there is a decrease in absorption. Fig. 5 illustrated the percentage of $\mathrm{H}_{2} \mathrm{O}_{2}$ scavenging capacity. The results of standard $\mathrm{ML}, \mathrm{MC}, \mathrm{L}$ and $\mathrm{C}$ were found to be $68.8 \%, 52.4 \%, 49.6 \%, 43.1 \%$ and $37.7 \%$ at higher concentration $(50 \mu \mathrm{g} / \mathrm{ml})$, whereas IC 50 values were obtained as $24.57,42.76,46.35,58.63,66.28 \mu \mathrm{g} / \mathrm{ml}$ respectively. Fig. 5 depicts that the test compounds effectively scavenge $\mathrm{H}_{2} \mathrm{O}_{2}$ radicals in concentration-dependent manner.

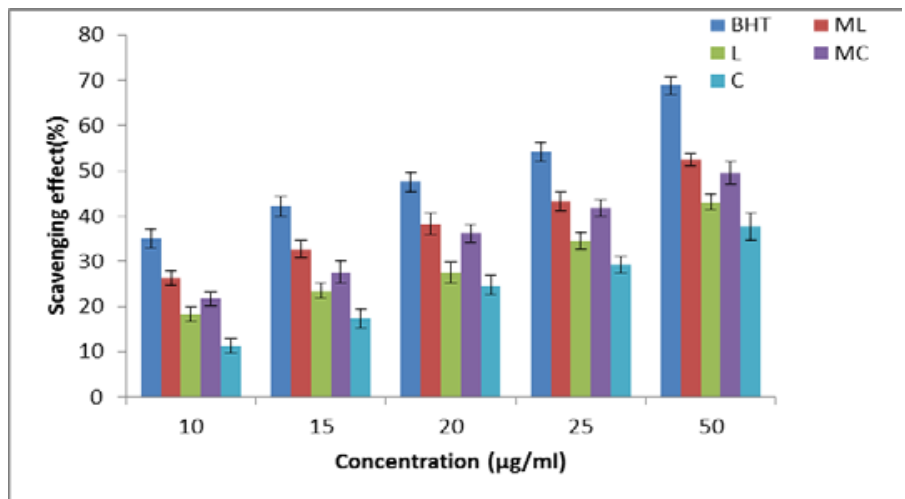

Fig. 5: Comparison of hydrogen peroxide scavenging activity of L-dopa (L),carbidopa (C), Cr(III) complex with L-dopa (ML), Cr(III) complex with carbidopa (MC) and BHT (butylated hydroxytolune) at different concentrations. Results are mean \pm standard deviation of three parallel measurements and data are evaluated by using one-way analysis of variance(ANOVA)

\section{CONCLUSION}

According to the different observations in the present study, it has been concluded that the Cr(III) complexes of L-dopa and carbidopa was synthesized and characterized by spectral measurements. The data show that $\mathrm{Cr}$ (III) reacts with the ligands in an acidic medium and bonded through the oxygen and nitrogen atoms of carboxylic and amino groups of the ligands.

Different in vitro antioxidant assay including ABTS, DPPH radical scavenging and hydrogen peroxide scavenging activity of L-dopa, carbidopa and their $\mathrm{Cr}(\mathrm{III})$ complexes were studied at different concentrations. The assay results of DPPH, ABTS and $\mathrm{H}_{2} \mathrm{O}_{2}$ showed excellent scavenging activity by synthesized complexes, may be due to binding of metal ion with levodopa and carbidopa, which is comparable to that of standard compound.

\section{AUTHOR CONTRIBUTIONS}

The work was carried out in collaboration between all the authors. Authors SSR and SP synthesized the products, carried out the antioxidant activities and drafted the manuscript. Authors SCS and PM managed the analysis of the study and literature searches. The article was read and approved by all the authors.

\section{CONFLICTS OF INTERESTS}

All authors have no conflicts of interests 


\section{REFERENCES}

1. Kiss T, Gergely A. Copper (II) and nickel (II) ternary complexes of L-Dopa and related compounds. J Inorg Biochem 1985;25:247-59.

2. Sanders LH, Greenamyre JT. Oxidative damage to macromolecules in human Parkinson disease and the rotenone model. Free Radical Biol Med 2013;62:111-20.

3. Halliwell B, Gutteridge JM. Free radicals in biology and medicine. Clarendon Press: Oxford. $2^{\text {nd }}$ Ed.; 1989. p. 23-30.

4. Jodko-Piorecka K, Litwinienko G. Antioxidant activity of dopamine and L-DOPA in lipid micelles and their cooperation with an analogue of $\alpha$-tocopherol. Free Radical Biol Med 2015;83:1-11.

5. Balik J, Kyselakova M, Vrchotova N, Triska J, Kumsta M, Veverka J, et al. Relations between polyphenols content and antioxidant activity in vine grapes and leaves. Czech J Food Sci 2008;26:25-32.

6. Pawar V, Joshi S, Uma V. Antibacterial and antioxidant properties of macrocyclic Schiff bases with vanadium (V) complexes. J Chem Pharm Res 2011;3:169-75.

7. Kostova I, Saso L. Advances in research of schiff-base metal complexes as potent antioxidants. Curr Med Chem 2013;20:4609-32.

8. Halliwell B. How to characterize a biological antioxidant. Free Radical Res Communications 1990;9:1-32.

9. Baral DK, Rout SS, Behera J, Si SC, Mohanty P. Kinetics and mechanism of interaction of hexaaquachromium (III) with lDopa in an aqueous medium: comparative antiparkinsonian studies. Transition Metal Chem 2011;36:231-6.

10. Aziza BK, Tofiqa DI. Kinetic and equilibrium comparison of the complexation reaction of Cis-and trans-forms of $\mathrm{Cr}(\mathrm{ox})_{2}\left(\mathrm{H}_{2} \mathrm{O}\right)_{2} \cdot \mathrm{xH}_{2} \mathrm{O}$ with alanine. Int J Chem Environ Eng 2012;3:34-8.

11. Rout SS, Kar DM, Pattanaik S, Si SC, Mohanty P. Kinetics and mechanism of reaction of cis- $\left[\mathrm{Cr}\left(\mathrm{C}_{2} \mathrm{O}_{4}\right)_{2}\left(\mathrm{H}_{2} \mathrm{O}\right)_{2}\right]$ with L-Dopa in an aqueous medium: comparative antiparkinsonian studies. Asian J Chem 2017;29:1555-60.

12. Blois MS, Antioxidant determinations by the effect of a stable free radical. Nature 1958;26:1199-200.

13. Gülçin İ. Antioxidant and antiradical activities of L-Carnitine. Life Sci 2006;78:803-11.

14. Re R, Pellegrini N, Proteggente A, Pannala A, Yang M, RiceEvans C. Antioxidant activity applying an improved ABTS radical cation decolarization assay. Free Radical Biol Med 1999;26:1231-7.

15. Gülçin I. Antioxidant activity of caffeic acid (3,4-dihydroxy cinnamic acid). Toxicology 2006;217:213-20.

16. Ruch RJ, Cheng SJ, Klaunig JE. Prevention and cytotoxicity and inhibition of intracellular communication by antioxidant catechins isolated from Chinese green tea. Carcinogenesis 1989;10:1003-8.
17. Siddiqi ZA, Khalid M, Kumar S, Shahid M, Noor S. Antimicrobial and SOD activities of novel transition metal complexes of pyridine-2, 6-dicarboxylic acid containing 4-picoline as an auxiliary ligand. Eur J Med Chem 2010;45:264-9.

18. Delaney S, Pascaly M, Bhattacharya PK, Han K, Barton JK. Oxidative damage by ruthenium complexes containing the dipyridophenazine ligand or its derivatives: a focus on intercalation. Inorganic Chem 2002;41:1966-74.

19. Serbest K, Colak A, Guner S, Karabocek S, Kormali F. Copper (II)-manganese (II) complexes' of $3, \quad 3-(1, \quad 3-$ propanediyldiimine) bis-(3-methyl-2-butanone) dioxime with superoxide dismutase-like activity. Transition Metal Chem 2001;26:625-9.

20. Vogel AI. Text Book of Practical Organic Chemistry. $5^{\text {Th }}$ Edition. Longman, London; 1989.

21. Patel KS, Patel JC, Dholariya HR, Patel VK, Patel KD. Synthesis of $\mathrm{Cu}$ (II), Ni (II), Co (II), and Mn (II) complexes with ciprofloxacin and their evaluation of the antimicrobial, antioxidant and antitubercular activity. Open J Metal 2012;2:49-59.

22. Koksal E, Gulcin İ, Beyza S, Sarikaya O, Bursal E. In vitro antioxidant activity of silymarin. J Enzyme Inhibition Med Chem 2009;24:395-405.

23. Brand-Williams W, Cuvelier ME, Berset CL. Use of a free radical method to evaluate antioxidant activity. LWT Food Sci Technol 1995;28:25-30.

24. Pattanaik S, Si SC, Nayak SS. Evaluation of free radical scavenging activity, wound healing activity and estimation of phenolic, flavonoid and proanthocyanidine contents of the plant "Crateva magna". Asian J Pharm Clin Res 2012;5(Suppl 3):168-71.

25. Shirwaikar A, Shirwaikar A, Rajendran K, Punitha ISJ. In vitro antioxidant studies on the benzyl tetra isoquinoline alkaloid berberin. Biol Pharm Bull 2006;29:1906-10.

26. Wolfeden BS, Willson RL. Radical cations as reference chromogen in kinetic studies of one-electron transfer reactions: pulse radiolysis studies of 2,29-azinobis-(3ethylbenzthiazoline-6-sulfonate). Chem Soc Perk Trans 1982;2:805-12.

27. Miller DD. Mineral. In: Fennema OR. Ed. Food Chemistry. Marcel Dekker, New York; 1996. p. 618-49.

28. Gülçin I, Elias R, Gepdiremen A, Boyer L. Antioxidant activity of lignans from the fringe tree (Chionantus virginicus L.). Eur Food Res Technol 2006;223:759-67.

29. Gulcin I. Comparison of in vitro antioxidant and antiradical activities of L-tyrosine and L-Dopa. Amino Acids 2007;32:431-8.

30. Hyslop PA, Hinshaw WA, Schraufstatter IU, Sauerheber RD, Spragg RG, Jackson JH, et al. Mechanism of oxidation-mediated cell injury. The glycolytic and mitochondrial pathways of ADP phosphorylation are major intracellular targets inactivated by hydrogen peroxides. J Biol Chem 1988;263:1665-75 